This item was submitted to Loughborough's Research Repository by the author.

Items in Figshare are protected by copyright, with all rights reserved, unless otherwise indicated.

\title{
Development of delamination in cross-ply laminates: effect of microstructure
}

PLEASE CITE THE PUBLISHED VERSION

PUBLISHER

(C) Trans Tech Publications, Switzerland

VERSION

AM (Accepted Manuscript)

LICENCE

CC BY-NC-ND 4.0

REPOSITORY RECORD

Khokhar, Zahid R., lan A. Ashcroft, and Vadim V. Silberschmidt. 2019. "Development of Delamination in Cross-ply Laminates: Effect of Microstructure". figshare. https://hdl.handle.net/2134/4638. 
This item was submitted to Loughborough's Institutional Repository (https://dspace.lboro.ac.uk/) by the author and is made available under the following Creative Commons Licence conditions.

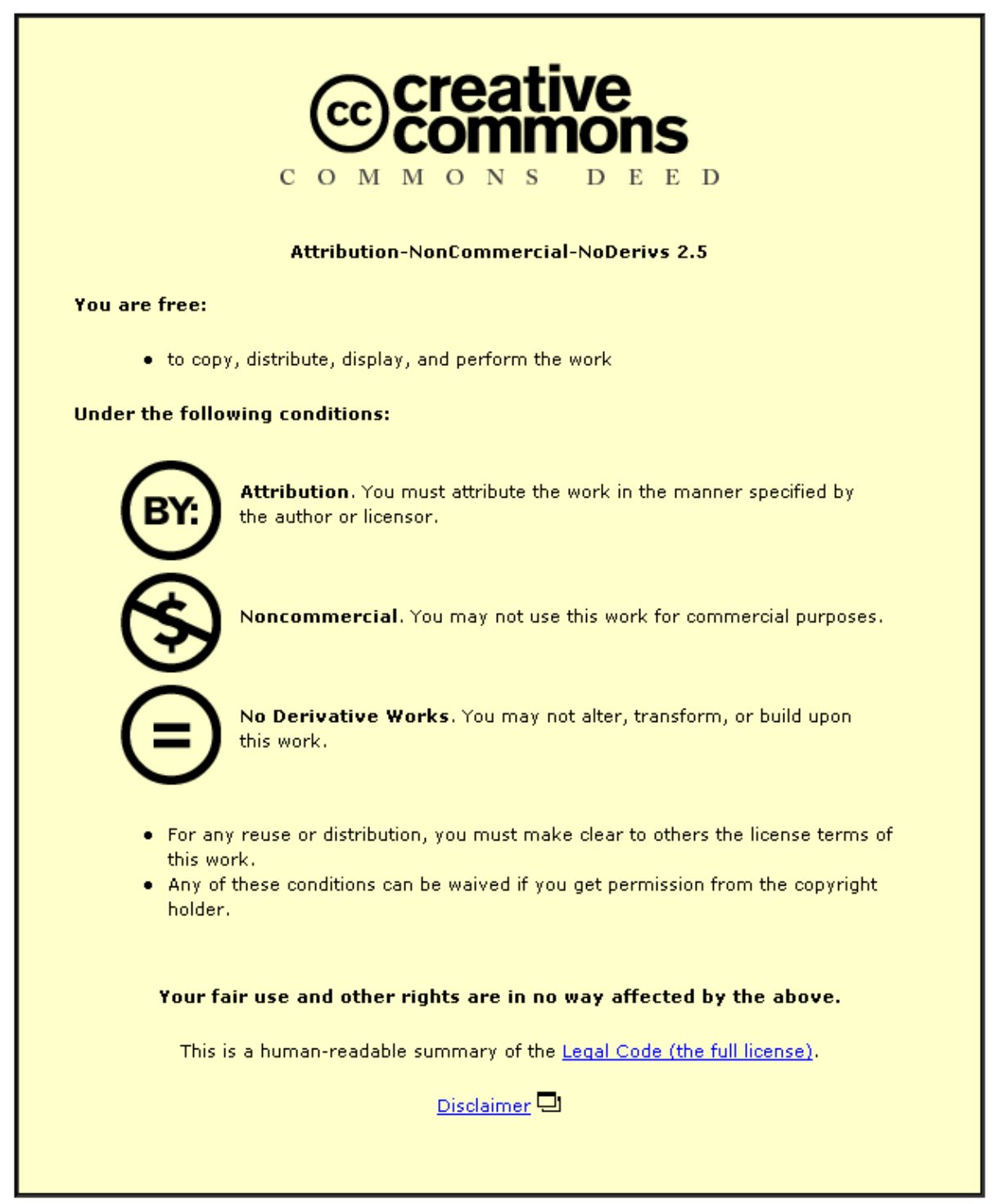

For the full text of this licence, please go to: http://creativecommons.org/licenses/by-nc-nd/2.5/ 


\title{
Development of Delamination in Cross-ply Laminates: Effect of Microstructure
}

\author{
Zahid R. Khokhar ${ }^{1}$, Ian A. Ashcroft ${ }^{2}$ and ${ }^{*}$ Vadim V. Silberschmidt ${ }^{3}$ \\ Wolfson School of Mechanical and Manufacturing Engineering, Loughborough University, \\ Loughborough, LE11 3TU, UK
}

1Z.R.Khokhar@lboro.ac.uk, ${ }^{2}$ I.A.Ashcroft@lboro.ac.uk, 32.Silberschmidt@lboro.ac.uk

Keywords: CFRP cross-ply laminates; Matrix cracking; Delamination; Cohesive zone modelling; Microstructural randomness.

\begin{abstract}
Various aspects of the effect of microstructural randomness exhibited by carbon fibrereinforced cross-ply laminates on the delamination damage mechanism is investigated in this paper. In the first part, the matrix cracks with different spacings measured in experiments are simulated using finite elements in order to obtain the levels of degradation and effective properties for a composite beam loaded in bending. The results show significant levels of degradation of obtained effective properties depicting the importance of accounting for the inherent stochasticity in these laminates. In the second part of the paper, initiation of delamination at an interface between $0^{\circ}$ and $90^{\circ}$ layers due to stress concentrations at tips matrix cracks is simulated for a beam under tension. Stochastic cohesive zone elements with fracture parameters presented as random fields are used to model this interface in a composite. Different values of the axial stress are obtained for initiation of damage for a number of realisations based on this approach. The results emphasize the need to take into consideration the microstructural randomness in fibre-reinforced laminates for adequate predictions of damage and load carrying capacities.
\end{abstract}

\section{Introduction}

Damage in CFRP cross-ply laminates: Effect of Microstructure. Failure in composite structures is often caused by the development of different mechanisms of damage acting in local zones of the structure. Initiation of a particular damage mode depends upon the type of loading, the lay-up and stacking sequence of the composite. Hence, all mechanisms of failure must be taken into account in simulations aimed at prediction of residual properties and performance of composites. The first stage of failure development in CFRP $\left[0_{\mathrm{m}} / 90_{\mathrm{n}}\right]_{\mathrm{s}}$-composite laminates under tensile loading conditions is characterised by a multiple generation and growth of transverse cracks in their inner $90^{\circ}$ layers. The place of the matrix crack's arrest at the interface between $0^{\circ}$ and $90^{\circ}$ layers is characterised by considerable stress concentration and often serves as a nucleus for initiation of delamination along such interfaces. The latter is due to the mismatch of the Poisson's ratios and inplane shear stiffness between differently oriented plies.

In most micromechanical analyses of fibre-reinforced composite materials, an assumption of spatial periodicity of their properties is employed: it is considered that the material has an ordered (deterministic) distribution of fibres. Still, in reality microstructure of fibre-reinforced composites is far from being ordered since fibres are usually randomly distributed in the matrix. It has been observed visually/experimentally that laminated composite materials exhibit a substantial extent of non-homogeneity in the spatial distribution of fibres. The manufacturing process of fibre-reinforced laminates leads to microscopic heterogeneity of the obtained materials. As a result of this nonuniformity, variations in the local properties of these laminates have been observed. This microstructural non-homogeneity plays an important part in the onset/propagation of damage and fracture processes that are also spatially non-uniform. Obviously, these features affect effective inservice properties of such laminates. 
Wang et al. [1] were among the first to regard the location of matrix cracks as a statistical quantity in their models for cross-ply laminates subjected to both static and fatigue loads. Baxevanakis et al. [2] demonstrated a high level of spatial non-uniformity for a composite by applying the image analysis technique to cross-sectional areas of T300/914 specimens. Silberschmidt showed that cross-ply carbon-epoxy laminates demonstrate a considerable extent of randomness in distributions of transverse cracks in $90^{\circ}$ layers [3] and studied the effect of microstructure randomness in the distribution of matrix cracks in these laminates [4]. Solutions for sets of cracks with minimum and maximum spacings were obtained, which in a majority of cases provided lower and upper bounds, respectively, for macroscopic properties of laminates. It was concluded that the behaviour of specimens with multiple matrix cracks cannot be always reduced to that of a single unit cell as an area traditionally limited by two neighbouring cracks under the assumption of equal crack spacing. Silberschmidt [5] further contributed to this topic by presenting a lattice model to study damage and fracture evolution in laminates, linking microstructural randomness with macroscopic properties and demonstrating that a random character of the fibres' distribution resulted in fluctuations of local elastic moduli in composites, the bounds of which depended on the characteristic length scale. Hence, the microscopically random nature of CFRP laminates has been considered by a number of researchers. This paper emphasizes the fact that this spatial non-uniformity should be directly taken into account while addressing damage scenarios in laminates.

This work is divided in two parts and is aimed at addressing the issue of microstructural randomness in CFRP laminates and its effect on damage in them and their effective properties. In the first part the effect of this randomness is studied in a composite beam in bending with direct introduction of matrix cracks and delamination zones into the model of laminates.

In the second part of the work only one matrix crack is introduced in the inner $90^{\circ}$ layers of the laminate, and processes of initiation and growth of delamination from the tips of the matrix crack are simulated for tension conditions. The potential path for the delamination growth in cross-ply laminates, i.e. a resin rich area between the $0^{\circ}$ and $90^{\circ}$ layers is represented by cohesive elements to analyze the initiation and development of delamination damage and to obtain the stress levels. The microstructural randomness is directly incorporated into the FE model by employing a half scatter of $50 \%$ for the fracture energy $G_{\text {IC }}$ in the cohesive law based on a two-parameter Weibull's probability distribution function.

The analyses in this paper are carried out using cohesive zone modelling (CZM) that has considerably changed the analysis of fracture development in the last few decades. Cohesive zone models or traction-separation models are predictive tools, which seem particularly attractive for practical applications since they can be incorporated effectively in computational FE codes.

Effect of microstructural randomness on flexural stiffness. Standard approaches and schemes, based on the equal spacing between adjacent matrix cracks in cross-ply laminates using representative volume elements, can not be employed to analyse the effect of the microstructural randomness. So, the first stage of the study is analysis of ensembles, comprising similar numbers of

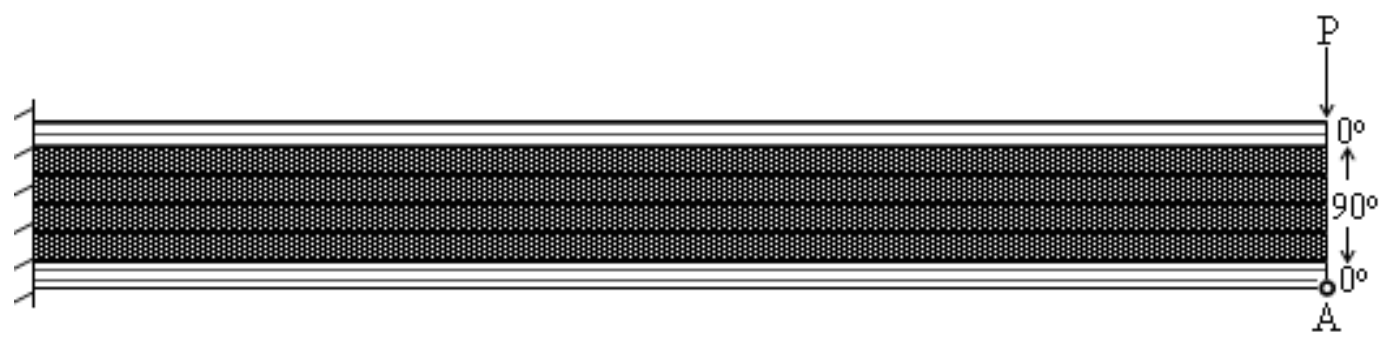

Fig. 1 Cross-ply laminate $\left[0_{1} / 90_{4} / 0_{1}\right]$ under bending 


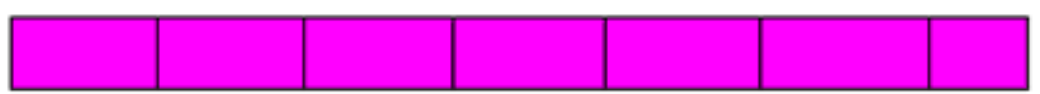

(a)
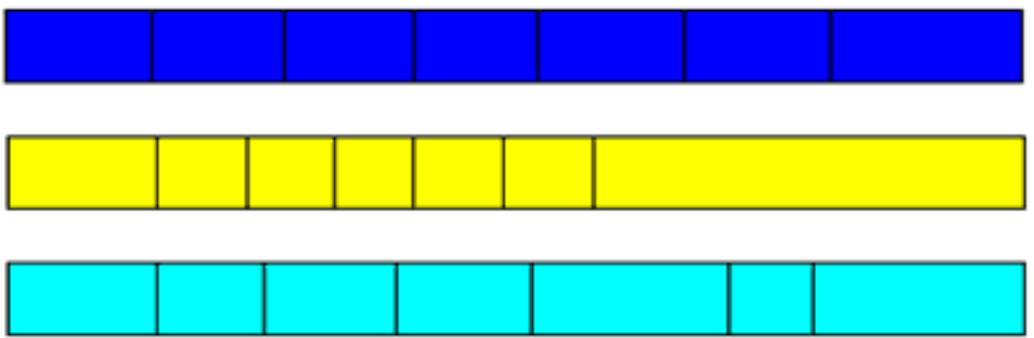

(d)

Fig. 2 Inner $90^{\circ}$ layers of laminates modelled with different crack spacings: (a) Maximum spacing; (b) Average spacing; (c) Minimum spacing; (d) Random spacing.

matrix cracks with adjacent delamination zones along interfaces between $0^{\circ}$ and $90^{\circ}$ layers of crossply laminates, for various types of spacing - minimum, maximum, average and random - between neighbouring transversal cracks. The respective magnitudes for spacings are taken from experimental data [5] for CFRP cross-ply laminates $\left[0_{1} / 90_{4} / 0_{1}\right]$ shown in Fig. 1 . The obtained results for flexural stiffness of laminates with different types of spacing vividly demonstrate the necessity to account for material's randomness.

All six plies of the studied laminate have a thickness of $0.125 \mathrm{~mm}$ with the Young's moduli of $E_{0}=132.4 \mathrm{GPa}$ and $E_{90}=9.0 \mathrm{GPa}$. Firstly, by analyzing an undamaged laminate beam, the equivalent modulus was calculated by applying a certain value of force to the undamaged laminate. In order to analyze the effect of microstructural randomness, the laminate with four different cases of matrix cracking subjected to same loading conditions was simulated using FE modelling. Three cases represent uniform distributions of six transverse cracks with various crack spacings $(0.4 \mathrm{~mm}$, $0.8 \mathrm{~mm}, 1.6 \mathrm{~mm})$ while the fourth case is the one with random crack spacings $(0.6 \mathrm{~mm}, 0.5 \mathrm{~mm}, 0.8$ $\mathrm{mm}, 1.1 \mathrm{~mm}, 1.5 \mathrm{~mm}, 0.4 \mathrm{~mm}$ ) shown schematically in Fig. 2.

All of the above mentioned cases of crack spacing are studied with different delamination sizes varying from zero (no delamination) to a maximum of $0.35 \mathrm{~mm}$ (Fig. $3, \mathrm{l}_{\mathrm{d}}$ is the delamination zone length). The centre of each delamination zone coincided with the tip of the transverse crack (Fig. 3). The effective flexural moduli of the laminate were obtained and compared. All the analyses were implemented with MSc Marc software with the same mesh densities. A large strain option was employed to incorporate properly the large deflections.

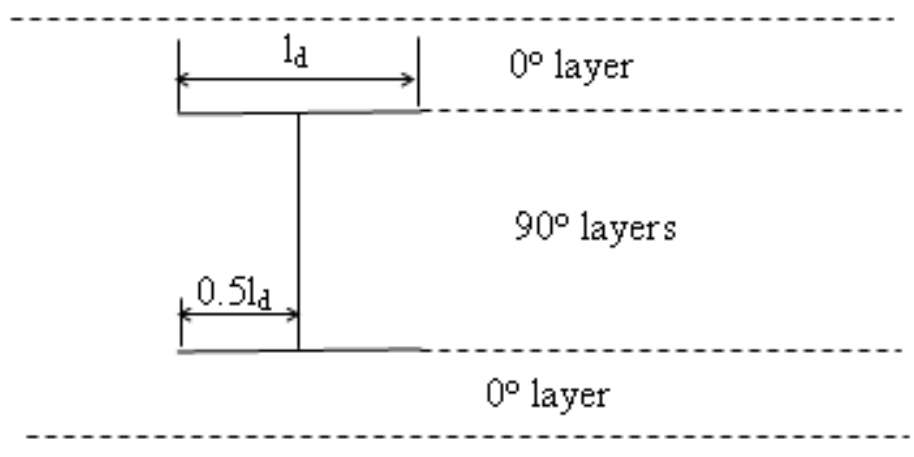

Fig. 3 Matrix crack with delamination zones between $0^{\circ}$ and $90^{\circ}$ layers 


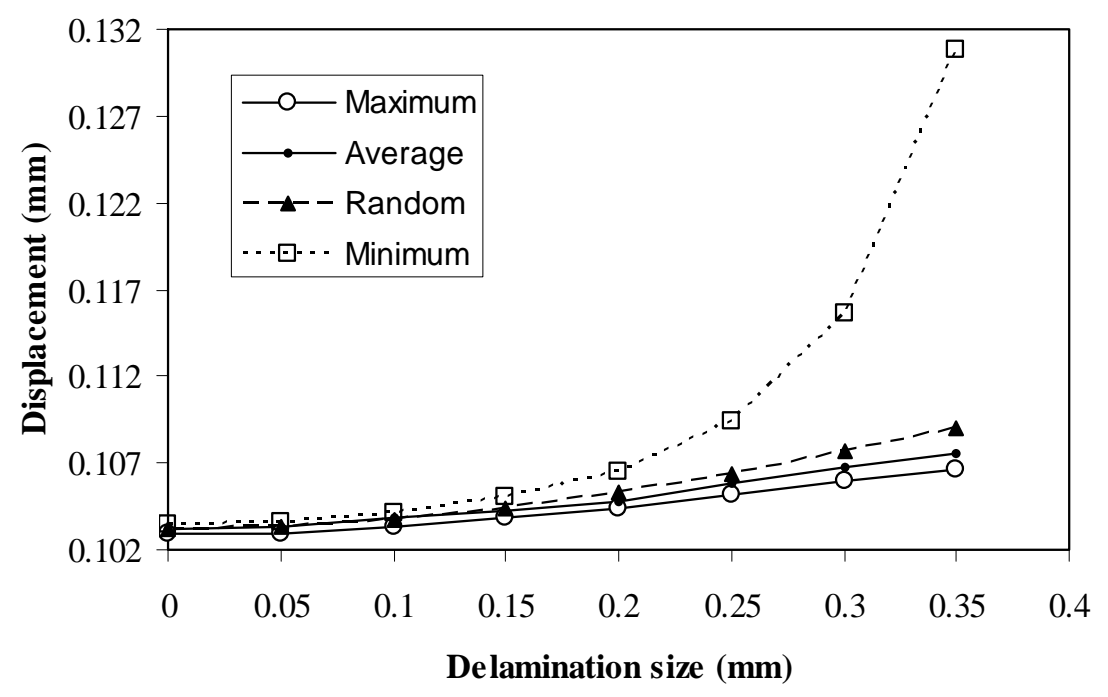

Fig. 4 Effect of delamination size on displacement in bending for beams with different crack spacings

The variation in maximum deflections for point A (Fig. 1) of the laminate beam without delamination zones and with different delamination sizes is presented in graphs of Fig. 4. The results of these simulations demonstrate that without the delamination zones introduced, the case with maximum crack spacing has a minimum displacement and the minimum crack spacing case has a maximum displacement while the other two cases have displacements within these two extremes. The differences due to these various crack spacings can be seen on a graph linking the delamination zone size and the displacement values (see Fig. 4).

As expected, the values of displacements increase with an increase in the delamination zone size. This increase in displacement is moderate for different crack spacings up to the point when the size of the delamination zone exceeds $0.2 \mathrm{~mm}$. After this point the displacement values for the minimum crack spacing case increase drastically. This indicates possible interactions between the neighbouring delamination zones generated by the associated matrix cracks. With a distance of 0.4 $\mathrm{mm}$ between the neighbouring cracks, the minimum crack spacing case will definitely have strong interactions and hence the displacement for a delamination zone of $0.35 \mathrm{~mm}$ is much higher for such laminate.

The values of the equivalent Young's modulus for all simulated cases were calculated and their change with the increase in the delamination size as compared to the effective modulus value of $E_{0}=93.2 \mathrm{GPa}$ (in undamaged state) is plotted in Fig. 5.

The effect can be further highlighted by calculating the value of damage for these cases, with the different sizes of delamination zones. The damage results depict that the laminate with the minimum crack spacing, lost maximum stiffness. This loss is $22.2 \%$ for the delamination size of $0.35 \mathrm{~mm}$ and the next higher value of decrease is $6.72 \%$ for the random spacing case. So there is a large loss of stiffness for the case with minimum crack spacing as compared to the other three cases having comparable amounts of damage (4.6\% for maximum spacing case).

To conclude this section, the results obtained from treatment of carbon fibre-reinforced cross-ply laminates as materials with random properties at the microstructural level show that this randomness must be adequately considered. Such high values of reduction in stiffness can lead to catastrophic failures of structures if only averaged distributions of defects would be used to predict the load carrying capacity. 


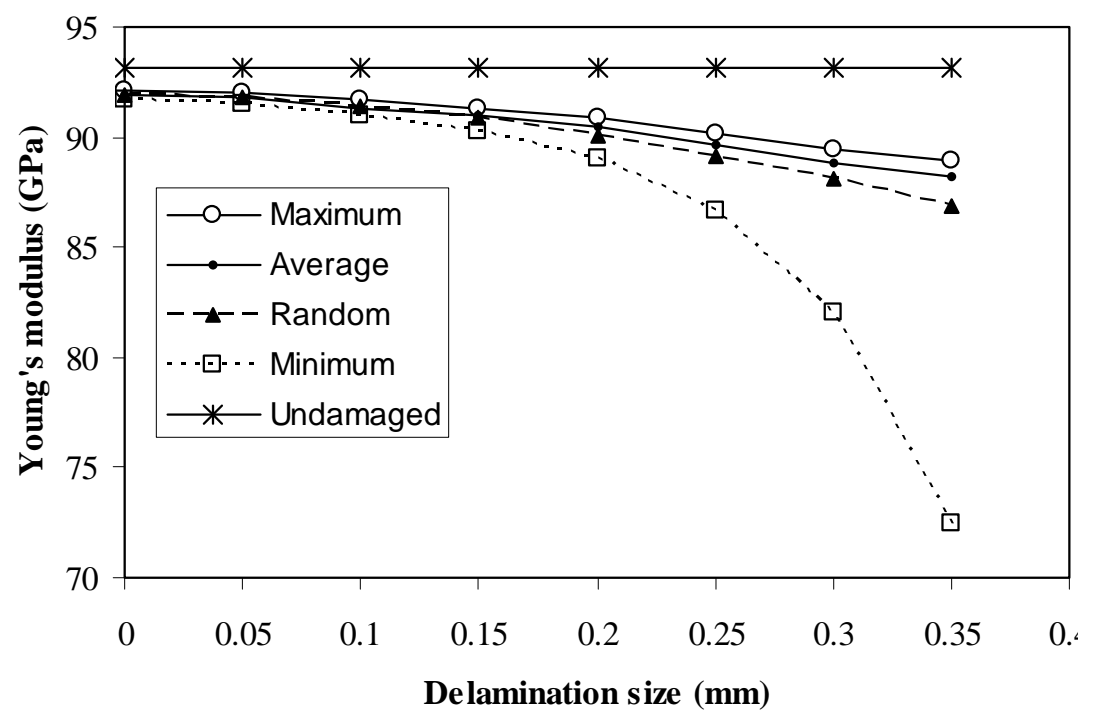

Fig. 5 Effect of delamination size on equivalent Young's modulus

\section{Matrix cracks as initiation points for delamination}

As it is well established, under the application of uniaxial axial loading, the early stage of damage in cross-ply laminates is dominated by transverse matrix cracking in $90^{\circ}$ plies. Matrix cracks develop in the fibre direction and extend across the laminates from the free edges of the test specimen. The analysis of transverse matrix cracking is important since it reduces the effective strength and stiffness of laminates; it also makes an ingress of moisture or other detrimental fluids easier. Transverse cracks induce local stress concentration at crack tips and can involve significant interlaminar delamination between $0^{\circ}$ and $90^{\circ}$ plies, due to the nature of cross-ply laminates. Transverse matrix cracking in $90^{\circ}$ plies also leads to load redistribution in adjacent $0^{\circ}$ plies [6].

This section is aimed at investigating the initiation and development of delamination damage from tips of a matrix crack and to obtain the stress levels that initiate this damage. The microstructural randomness exhibited by the laminates under study is accounted for to study its effects on the stresses and damage evolution.

A three-dimensional cross-ply laminate model is developed in finite element software MSc Marc. The layup is as shown in Fig. 6 with a matrix crack introduced within the $90^{\circ}$ layers. A bilinear traction-separation law has been employed to model the delamination zone.

The material properties of the simulated laminate and cohesive parameters are given in Table 1.

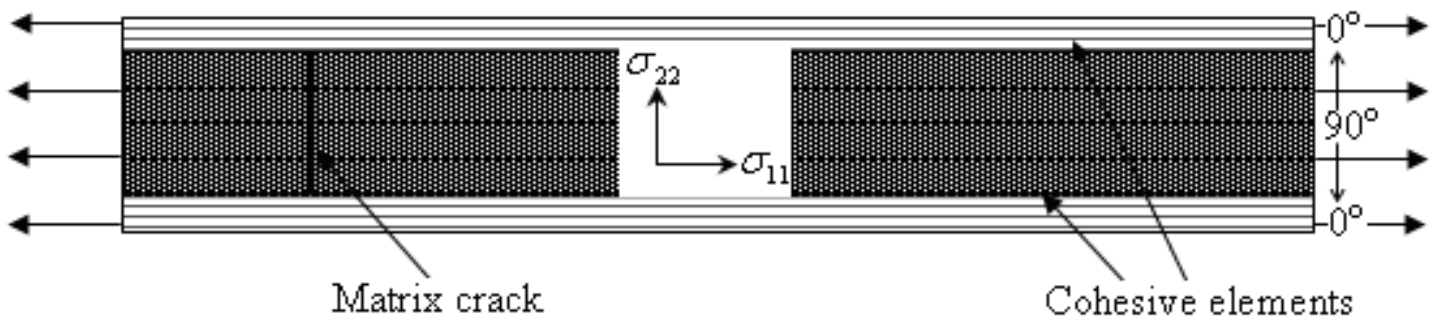

Fig. 6 Cross-ply laminate $\left[0_{1} / 90_{4} / 0_{1}\right]$ with matrix crack under tension 
Table. 1 Material properties for laminate and cohesive parameters [7]

\begin{tabular}{cccccc}
\hline \hline $\begin{array}{c}E_{11} \\
{[\mathrm{GPa}]}\end{array}$ & $\begin{array}{c}E_{22}=E_{33} \\
{[\mathrm{GPa}]}\end{array}$ & $\begin{array}{c}G_{12}=G_{13} \\
{[\mathrm{GPa}]}\end{array}$ & $\begin{array}{c}G_{23} \\
{[\mathrm{GPa}]}\end{array}$ & $v_{12}=v_{13}$ & $v_{23}$ \\
\hline 122.7 & 10.1 & 5.5 & 3.7 & 0.25 & 0.45 \\
\hline \hline
\end{tabular}

\begin{tabular}{ccccc}
\hline \hline $\begin{array}{c}G_{\mathrm{IC}} \\
{\left[\mathrm{kJ} / \mathrm{m}^{2}\right]}\end{array}$ & $\begin{array}{c}G_{\text {IIC }} \\
{\left[\mathrm{kJ} / \mathrm{m}^{2}\right]}\end{array}$ & $\begin{array}{c}\sigma_{1} \\
{[\mathrm{MPa}]}\end{array}$ & $\begin{array}{c}\sigma_{2} \\
{[\mathrm{MPa}]}\end{array}$ & $\begin{array}{c}\sigma_{3} \\
{[\mathrm{MPa}]}\end{array}$ \\
\hline 0.969 & 1.719 & 100 & 100 & 80 \\
\hline \hline
\end{tabular}

Here, $G_{\text {IC }}$ and $G_{\text {IIC }}$ are the values of fracture energy in mode I and II respectively. $\sigma_{1}$ is the normal tripping traction while $\sigma_{2}$ and $\sigma_{3}$ are the values of the shear tripping tractions. Fracture along the interface between $0^{\circ}$ and $90^{\circ}$ plies has a mixed-mode nature and needs to be accounted for by the cohesive zone model while dealing with interfacial cracks. The mode-mixity was taken into account by introducing the shear/normal coefficients for maximum stress (traction of the cohesive law) and cohesive energy (fracture energy) into the finite element model.

Displacement-controlled analysis was performed by applying displacement at the ends of the model. Three different analyses were performed to highlight various issues as summarized:

Case A. Model without a crack and cohesive elements between $0^{\circ}$ and $90^{\circ}$ layers using uniform fracture properties throughout the cohesive layer.

Case $B$. Model with one crack and cohesive elements between $0^{\circ}$ and $90^{\circ}$ layers using uniform fracture properties throughout the cohesive layer.

Case C. Model with one crack and cohesive elements between $0^{\circ}$ and $90^{\circ}$ layers using random fracture properties based on a 2-parameter Weibull's distribution [8] (multiple realizations presented). A value of half scatter of $50 \%$ of properties is selected to underline the effect of the material's stochastic nature on the course of damage initiation and propagation. This is achieved by introducing cohesive zone properties in terms of the fracture energy. Simulations are carried out in order to highlight the effect of varying fracture energy $G_{\text {IC }}$ since the ability of a structure to resist defect propagation is characterized by the fracture toughness of the material. The fracture energy of cohesive elements is considered to be represented by a distribution based on a two-parameter Weibull's probability density function for the scatter width $\left[G_{\text {IC }}{ }^{\min }=0.5 G_{\text {IC }}, G_{\text {IC }}{ }^{\max }=1.5 G_{\text {IC }}{ }\right.$. The number of data points generated is equal to the number of nodes in the layer of cohesive elements and assigned to all the nodes in the cohesive layer of the finite element model.

The calculated values of axial stress $\sigma_{11}$ at the points of initiation and of full damage are compared for all these analyses. Comparing the first two cases, delamination in the beam without a crack initiates when the stress level reaches a value of 11140 Pa while for the case with a crack it develops at a lower stress level of $3590 \mathrm{~Pa}$ which shows that the delamination damage develops from the crack tips (see Fig. 7) and releases the local stress concentrations.

Cases B and C are same in geometry but have different types of distribution of fracture properties along the cohesive layer, uniform in Case $B$ and random in Case $C$ where these properties are based on the two-parameter Weibull's distribution. A number of statistical 


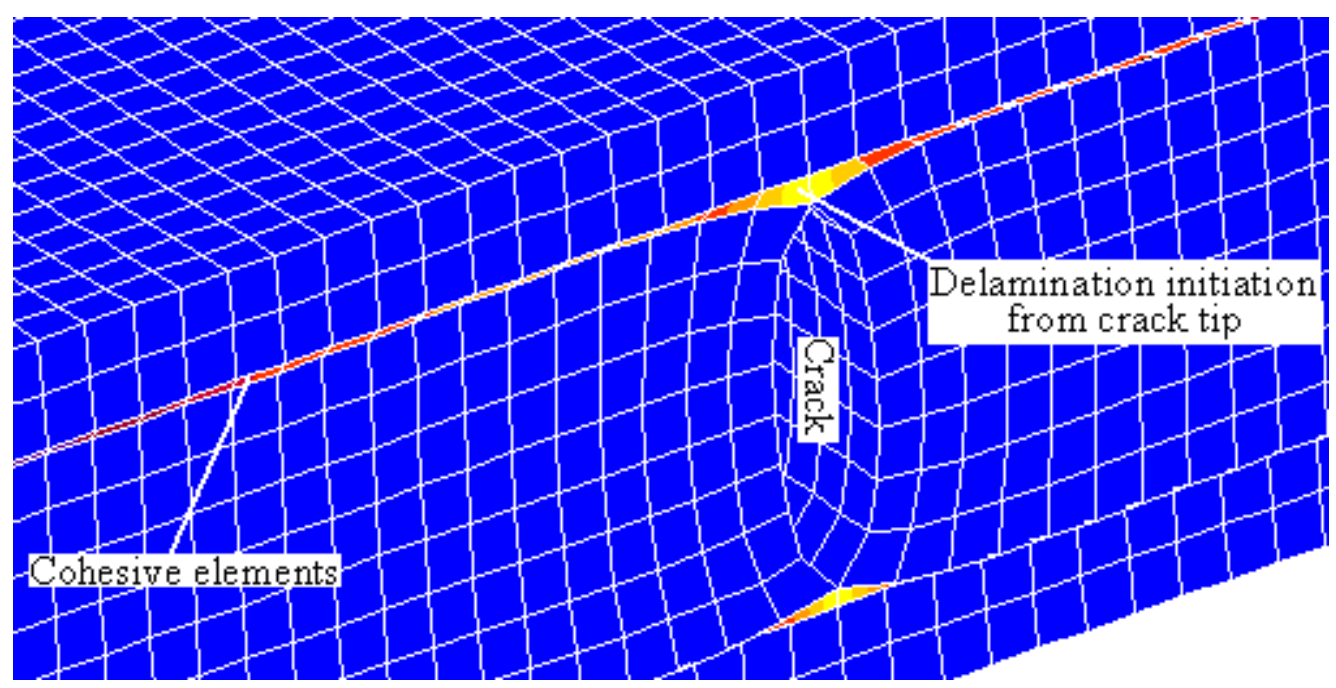

Fig. 7 Damage initiation in $\left[0_{1} / 90_{4} / 0_{1}\right]$ laminate under tension- A close up

realisations of distribution of fracture properties are simulated for random fracture properties based on the Weibull's probability distribution. The obtained results for the values of the critical stress linked to the initiation of delamination present a wide scatter with some values exceeding the one in case B with uniform fracture properties.

An important observation is that in $60 \%$ of simulations the predicted value of stress at damage initiation point is much lower-up to $45 \%$. These results demonstrate that it is really important to account for the microstructural randomness exhibited by these laminates as this can have a profound effect on damage initiation and propagation. Using uniform properties models may predict values of stresses and damage that are unreliable for safe structural applications.

\section{Conclusions}

The damage and failure mechanisms of composites, which are essentially interlinked with nonhomogeneity and randomness at the microstructural level, are investigated in this paper. In the first part of the paper composite beams, comprising similar numbers of matrix cracks with adjacent delamination zones along interfaces between $0^{\circ}$ and $90^{\circ}$ layers of cross-ply laminates, are studied for various types of spacing. The results obtained show high values of reduction in stiffness of the considered beams compared to the undamaged one. In the second part, initiation and development of delamination damage from tips of a matrix crack are analysed. Values of axial stress that initiate the delamination between $0^{\circ}$ and $90^{\circ}$ layers demonstrate a large scatter when introducing the fracture energy as a random variable based on the Weibull's probability distribution. Results of number of realizations underline the need to account for the microstructural randomness since predictions based on the uniform or mean properties data for these laminates could significantly overestimate the critical value of stress necessary to initiate material's damage/fracture. More than $60 \%$ of the realizations predict the value of axial stress at damage initiation point lower than the value obtained for the case with uniform fracture properties along the cohesive layer.

The work presented here studied delamination initiation in the stress concentration zone caused by only one matrix crack. Future work will include introducing more than one matrix cracks and investigation of interactions between delamination and matrix cracks and the stress levels and damage values that initiate such interactions. 


\section{References}

[1] A.S.D. Wang, P.C. Chou and S.C. Lei, A stochastic model for the growth of matrix cracks in composite materials, Journal of Composite Materials, 18 (1984), pp. 239-254.

[2] C. Baxevanakis, D. Jeulin and J. Renard, Fracture statistics of a unidirectional composite, International Journal of Fracture, 73 (1995), pp. 73-149.

[3] V.V. Silberschmidt, Scaling and multifractal character of matrix cracking in carbon fibrereinforced cross-ply laminates, Mechanics of composite materials and structures, 2 (1995), pp. 243-255.

[4] V.V. Silberschmidt, Matrix cracking in cross-ply laminates: effect of randomness, Composites Part A: Applied Science and Manufacturing, 36 (2005), pp. 129-135.

[5] V.V. Silberschmidt, Effect of micro-randomness on macroscopic properties and fracture of laminates, Journal of Material Science, 41 (2006), pp. 6768-6776.

[6] J.-M. Berthelot, Transverse cracking and delamination in cross-ply glass-fibre and carbon-fibre reinforced plastic laminates: Static and fatigue loading, Applied Mechanics Review, 56 (2003), pp. 112-147.

[7] A. Turon, P.P. Camanho, J. Costa and C.G. Dávila, An Interface Damage Model for the Simulation of Delamination under Variable-mode Ratio in Composite Materials, NASA/TM2004-213277.

[8] Z.R. Khokhar, I.A. Ashcroft and V.V. Silberschmidt, Simulations of delamination in CFRP laminates: Effect of microstructural randomness, Submitted in Journal of Computational Materials Science. 